\title{
COMPETÊNCIAS DE ALUNOS-PROFESSORES: UM OLHAR SOBRE A FORMAÇÃO DOCENTE INICIAL EM LÍNGUA INGLESA
}

\author{
Josimayre Novelli* \\ Elaine de Castro ${ }^{* *}$
}

\begin{abstract}
RESUMO: Este estudo foi realizado com base nas experiências de alunas do curso de Letras com habilitação em Língua Inglesa de universidades localizadas no estado do Paraná, entre 1998 e 2017, visando investigar a relevância do desenvolvimento de competências do agir docente e linguísticodiscursivas relacionadas à prática docente em contextos educacionais diversos. Considerando as disciplinas e atividades acadêmicas ofertadas na graduação em Letras, as quais visam ao desenvolvimento de tais competências, muitas vezes, de maneira dissociada (CASTRO, 2006) e com foco no alunoprofessor, sendo visto como aprendiz de professor e não aluno de uma língua estrangeira (LE) (JOHNSON e FREEMAN, 2001), foi conduzida uma pesquisa de natureza qualitaitva por meio da aplicação de um questionário de cunho dissertativo com o intuito de discutir o papel das competências na atuação profissional docente e como essa possível relação é vivenciada e interpretada por esses profissionais desde o início de seu processo de formação docente na graduação. Deste modo, esse trabalho espera contribuir com as pesquisas em formação docente na área de Letras no que tange à construção de competências profissionais, sobretudo na formação docente inicial.
\end{abstract}

Palavras-chave: Formação Docente; Competências; Língua Inglesa.

\section{Introdução}

Nas disciplinas e atividades acadêmicas ofertadas nos cursos de formação de professores de Língua Estrangeira (doravante LE), observa-se uma dicotomia representada,

\footnotetext{
* Doutora em Estudos da Linguagem pela Universidade Estadual de Londrina (Uel). Diretora do Núcleo de Educação a Distância da Universidade Estadual de Maringá (Uem).

** Mestre em Estudos Linguísticos: Ensino-aprendizagem de Línguas pela Universidade Estadual de Maringá (Uem). Atua como professora colaboradora na Unespar - Campus de Apucarana.
} 
de um lado pelo desenvolvimento de competências docentes, e de outro, por competências linguístico-discursivas (CASTRO, 2006). Tal aspecto ressalta a necessidade de se considerar, de modo geral, os conhecimentos a serem mobilizados na formação docente, e não a construção de competências mais e menos relacionadas com o agir docente.

Não questionamos aqui a importância de uma competência em detrimento de outra na formação dos professores de LE, mas nos referimos a aspectos de conteúdo presentes na formação inicial do professor. Como Perrenoud (2002) apontou em seus estudos, o domínio didático-pedagógico de professores é, muitas vezes, inferior ao domínio de aspectos relacionados à disciplina na qual lecionam. O autor defende que o domínio do conteúdo é algo positivo na formação docente, porém, forma-se uma lacuna entre conteúdo e como ensiná-lo.

Por este viés, de acordo com as noções de conhecimento disciplinar e pedagógico de Shulman (1987), surge a questão de como associar as disciplinas que envolvem tanto competências docentes quanto linguístico-discursivas na graduação, de modo a promover a formação docente voltada à prática pedagógica como um todo e, por sua vez, reduzindo a distância entre teoria e prática.

Para tanto, propomos essa pesquisa com o intuito de evidenciar o modo como as disciplinas ofertadas em cursos de graduação em Letras contemplam competências necessárias à formação docente, ao investigarmos como alunos-professores percebem tais competências e como as relacionam à sua atuação profissional. Com isso, buscamos desenvolver uma reflexão sobre o papel das competências na prática docente e, assim, contribuir com as pesquisas em formação docente na área de Letras no que tange à construção de competências profissionais.

\section{Graduação em Letras}

Como ponto de partida desse estudo, o curso de Letras consiste no processo de formação docente, no qual competências vinculadas tanto à qualificação profissional quanto à aspectos relacionados à educação e ensino são contempladas. Com a promulgação 
das Diretrizes Curriculares Nacionais para cursos de licenciatura (doravante DCN), em 1996, tais competências foram pensadas de modo a organizar o currículo com vistas à qualidade da formação docente. De acordo com as premissas das DCN,

O objetivo do Curso de Letras é formar profissionais interculturalmente competentes, capazes de lidar, de forma crítica, com as linguagens, especialmente a verbal, nos contextos oral e escrito, e conscientes de sua inserção na sociedade e das relações com o outro (BRASIL, 2001, p. 30).

Assim sendo, a graduação em Letras deve ter estruturas flexíveis para a formação de um profissional capaz de atuar no mercado de trabalho, contemplando o desenvolvimento de habilidades necessárias para as competências desejáveis a este profissional. Ainda, o curso deve priorizar a abordagem pedagógica e articular ensino, pesquisa e extensão, proporcionando ao graduando a autonomia universitária, por meio das atividades curriculares (BRASIL, 2001).

Nesta ordem, espera-se desenvolver com a formação inicial do professor de LE o domínio linguístico-comunicativo da língua objeto de estudo, “[...] em termos de sua estrutura, funcionamento e manifestações culturais". Por meio do domínio da língua tanto materna quanto estrangeira, o curso de Letras deve contribuir com a formação de profissionais para atuar em diversas profissões: "professores, pesquisadores, críticos literários, tradutores, intérpretes, secretários, etc" (BRASIL, 2001. p. 30).

Ainda no documento, são contempladas qualidades pessoais relacionadas às habilidades pedagógicas, responsabilidade social e educacional, reforçando o compromisso ético da atuação desse profissional, além da sua capacidade de reflexão sobre a linguagem como objeto de estudo e sobre sua própria formação.

De acordo com Bonfim e Conceição (2014), as competências relacionadas à docência aparecem bem delimitadas no documento, enquanto as demais são abordadas de um modo geral, como na formação de outras profissões. Portanto, os conteúdos curriculares são associados aos Estudos Linguísticos e Literários articulados à prática, como consta em seu texto: 
No caso das licenciaturas deverão ser incluídos os conteúdos definidos para a educação básica, as didáticas próprias de cada conteúdo e as pesquisas que as embasam. O processo articulatório entre habilidades e competências no curso de Letras pressupõe o desenvolvimento de atividades de caráter prático durante o período de integralização do curso (BRASIL, 2001, p. 31).

Em conjunto com o currículo e de acordo com a Resolução CNE/CP 2, de 19 de fevereiro de 2002, a carga horária das licenciaturas deve corresponder a 2800 horas, sendo 1800 horas de aulas de conteúdos curriculares científico-culturais, 400 horas de prática, 400 horas de estágio supervisionado e 200 horas de atividades acadêmicas científico-culturais.

É neste âmbito que surgem algumas preocupações com relação aos objetivos da formação profissional do curso de Letras. Paiva (2005) questiona o currículo da dupla habilitação (Língua Portuguesa e mais uma LE), pois tal modelo de licenciatura compromete a qualidade do curso, ao priorizar conteúdos de língua portuguesa e reduzir o espaço das LE na grade curricular. Além disso, a carga horária supracitada de 2800 horas foi definida considerando a formação em uma única habilitação.

Em meio aos objetivos direcionados nas DCN (BRASIL, 2001), é necessário pensar nas políticas que favorecem a aproximação entre o discurso legislativo e a realidade da profissão. Como constatou Perin (2003) em suas observações entre membros das escolas públicas (professores, alunos, gestores), ao ver do governo, basta melhorar a competência linguística do professor e assim, a melhora na aprendizagem é evidente. A autora reforça a análise do contexto escolar como um todo para favorecer o ensino-aprendizagem.

Os estudos de Bonfim e Conceição (2014) sobre competências-base na formação docente, envolvendo problemas na qualificação da formação profissional (SCHULZ, 2000; WILBUR, 2007), evidenciaram que, ainda hoje, questões como insuficiência da competência linguística, ineficácia do estágio e de políticas educacionais rigorosas se fazem presentes. As autoras acreditam na necessidade de se repensar a formação de professores para se sair deste ciclo vicioso (BONFIM e CONCEIÇÃO, 2014). 
A partir desses pressupostos, a formação de professores surgiu como uma possível solução para problemas advindos desde a formação docente inicial e que perpetram a atuação profissional, cabendo ao processo de formação docente continuada abordar novos desafios advindos da prática. Por este ponto de vista, é evidente que repensar a formação docente engloba seus estágios inicial e continuado.

\section{Formação de Professores}

Sabemos que os programas de formação docente têm como objetivo reunir professores com a intenção de compartilhar experiências, desenvolver e consolidar a prática do professor, ao proporcionar conhecimento teórico, prática, pedagógico, curricular, dentre outros. Porém, alguns pontos limitadores como a imposição de algums perspectivas teórico-metodológicas em detrimento de outras, bem como a ausência de compartilhamento de experiências ou a distância entre teoria e prática afetam este trabalho. Essas questões dialogam com a afirmação de Gimenez (2013), ao dizer que muitos dos problemas de sala de aula não são contemplados durante a licenciatura, sendo esta forma de acesso ao conhecimento predominantemente teórico.

Corroborando essa visão, Wallace (1991) contrastou o prestígio entre a formação docente e a de outras profissões. Ao considerar a primeira, esta acontece muitas vezes imposta, fora do horário de trabalho do professor, sem a preocupação com acesso a internet ou outras tecnologias, e é comum o professor ser tratado como um profissional sem experiências. Enquanto a formação de um doutor, por exemplo, envolve prestígio e um tratamento diferenciado, no qual a intenção é de se obter ainda mais conhecimento.

Nesta ordem, como afirmou Wallace (1991, p. 3), "nenhum aprendizado acontece no vácuo" e ao pensar no momento em que a LE se encontra, desde o fim do século XX, com a explosão do processo de ensino e aprendizagem de línguas, a demanda por profissionais dessa área, consequentemente, aumentou. Portanto, é imprescindível uma formação adequada. 
Para tanto, a formação de professores, tanto a inicial quanto a continuada, é fundamentada em três principais modelos conceituais, nos quais os objetivos e as competências, bem como o papel dos envolvidos - professor e aluno-professor - diferem: 1) formação artesanal; 2) formação tecnicista; 3) formação reflexiva. Passo, então, para a definição desses três modelos de formação.

\section{Formação Artesanal}

Este modelo, também chamado de craft (WALLACE, 1991), é caracterizado por um processo de aprendizagem por meio da observação e imitação do ensino de um mestre experiente. Deste modo, há tentativas seguidas de erros das técnicas de ensino observadas e os conhecimentos do professor recebem atenção principal (ZEICHNER, 1983).

Richards (2002) associa este modelo à utilização de um conjunto de habilidades ensinadas, as quais não necessitam de um método, mas sim da personalidade e capacidade do professor observador. Em outras palavras, ao analisar a prática pedagógica de outro profissional mais experiente, o professor irá reproduzir as técnicas de acordo com seu julgamento e abordagem (RICHARDS, 2002).

Nesta ordem, por se tratar da observação de um professor formador acima de saberes teóricos, tal modelo linear e mecânico não abre espaço para o desenvolvimento do conhecimento científico, resultando em competências automatizadas e sem reflexão para a tomada de decisões.

\section{Formação Tecnicista}

Formação esta também chamado de racionalidade técnica (SCHÖN, 2000), o qual consiste na resolução de problemas advindos da prática por meio do conhecimento científico (WALLACE, 1991), sendo a prática de ensino do professor premeditada por conceitos informados pelo seu formador. 
Neste modelo, a aprendizagem é vista como aquisição e automação de técnicas de ensino relacionadas à aprendizagem do aluno, que podem ser "passadas" ao professor anteriormente à prática, implicando na aquisição de uma completude de conhecimentos relacionados ao ensino (JOHNSTON; FREEMAN, 2001).

Tal perspectiva também foi criticada, uma vez que o professor em formação é visto como recipiente passivo de conhecimento, sem ao menos desenvolver senso crítico ou participar ativamente de sua própria formação, além de desconsiderar a prática também como momento de formação docente (SCHÖN, 2000).

\section{Formação reflexiva}

Com base nos estudos de Schön (2000), este modelo abordou os conceitos de conhecer-na-ação, reflexão-na-ação, reflexão-sobre-a-ação e reflexão-sobre-a-reflexão-naação. Neste ponto, a partir dos outros modelos, a reflexão permite aos professores questionar seu contexto de atuação, analisar ações e confrontar teorias (ZEICHNER, 1983).

Neste âmbito, o professor formador é coconstrutor do conhecimento em parceria com o professor em formação. Assim, os conhecimentos recebidos tanto durante a formação, sejam de ordem teórica ou não, quanto àqueles adquiridos na prática da profissão, devem ser englobados (WALLACE, 1991).

O modelo de reflexão é um misto dos modelos artesanal e tecnicista, ao considerar as práticas observáveis como meios de se alcançar objetivos e os conceitos teóricos que fundamentam tais escolhas práticas. Assim, a reflexão leva o professor a pensar e/para agir em contexto.

A partir desses três modelos, é possível perceber que a formação docente é um processo, o qual não ocorre somente na graduação em Letras ou durante seu decurso, mas que se inicia na licenciatura e permanece totalmente envolvido na execução dos ofícios docentes. Tal processo envolve teoria, prática e reflexão, de um modo conjunto e interminável. 
Partindo dessa perspectiva, a virada sócio-histórico-cultural nas pesquisas e nas práticas de formação de professores conduziu os estudos a uma visão da aprendizagem como meio de transformação da participação dos indivíduos em práticas sociais situadas, as quais influenciam suas identidades, conhecimentos e relações interpessoais (MATEUS, 2009). Deste modo, a aprendizagem deixou de ser vista como uma resolução de problemas e passou a constituir um processo de mudanças, e no caso, da formação de professores, ressignificações de papéis e valores evidenciaram a aproximação entre teoria e práxis.

Deste modo, a reflexão crítica vista como um processo de pensamento orientado na formação docente, conforme Contreras (2002, p. 179),

[...] tem um propósito muito claro de "definir-se" diante dos problemas e atuar consequentemente, considerando-os como situações que estão além de nossas próprias intenções e atuações pessoais, para incluir sua análise como problemas que têm uma origem social e histórica"

Além de contribuir com a formação docente, para Abkari (2007), a reflexão crítica pode munir o professor de línguas de técnicas que o conscientizem de suas próprias ações dentro e fora de sala de aula. Porém, o autor enfatiza a importância de promover e avaliar adequadamente essas reflexões com base tanto teórica quanto prática. Ao mesmo passo que pode ser positiva para uma postura mais emancipatória e ativa, a reflexão crítica com base prioritariamente na experiência prática pode limitar o profissional, ao menosprezar discussões teóricas que proporcionam procedimentos e técnicas para sua atividade docente, e assim o distanciando de suas comunidades discursivas (ABKARI, 2007).

\section{Competências do Aluno-Professor}

Inicialmente, nos estudos de Castro (2006), a formação docente é associada ao desenvolvimento de competências tanto linguístico-discursivas quanto docentes, apresentadas mais adiante neste trabalho. Assim, ao se pensar na licenciatura em Letras, a construção de competências docentes tem papel prioritário, uma vez que a formação docente visa 
capacitar um profissional que reconheça, aprecie e aja de modo eficaz no ensino de línguas (CASTRO, 2006).

Nesta ordem, de acordo com Perrenoud (2000, p. 15), competência é a "[...] capacidade de mobilizar diversos recursos cognitivos para enfrentar um tipo de situação”. Por isso, as competências não são 'ensinadas' ao professor durante a graduação, mas envolvem um processo de adaptação entre determinar e realizar uma ação relacionada a uma situação específica.

Mais especificamente na formação de professores, as competências precisam unir os saberes de cada uma das disciplinas do curso, em termos de conteúdos a serem ensinados, aos objetivos da aprendizagem. Assim, para desenvolver as competências necessárias para seu ofício, o graduando e também seu formador precisam considerar que elas são construídas tanto na formação quanto nas situações advindas da prática.

Além de se reconhecer a importância dessas competências para o professor de LE, Jorge (2001, p. 507) aponta três competências essenciais:

(a) uma competência que inclui conhecimento e articulação de bases teóricas que fundamentam o ensino de LE, tratados pela linguística aplicada, assim como o desenvolvimento de habilidades que permitam a análise (para consequente intervenção) de diferentes contextos de ensino, tratados pela área de educação; (b) uma competência que orienta o planejamento do ensino, elaboração de materiais, etc., que pressupões conhecimento de diferentes métodos e estratégias de ensino que possam ser adequados à diversidade de abordagens de aprender e ensinar; e (c) uma competência que permita ao professor investir em sua formação continuada, por meio de prática reflexiva e capacidade de pesquisar a sala de aula.

Por este viés, a primeira competência apresentada se refere aos saberes relacionados à formação teórica do professor, pelos quais ele irá se basear para praticar seu ofício. Em seguida, ao demandar conhecimento de métodos e estratégias de ensino e, posteriormente, a formação continuada, as demais competências evidenciam uma conexão entre os saberes teóricos e práticos para o desenvolvimento do professor em serviço.

Deste modo, o agir docente é intimamente ligado às competências do próprio docente. São elas, que, por direcionarem as atitudes docentes no decorrer de situações no 
contexto de ensino e aprendizagem, caracterizam o docente como profissional. Corroborando a esta visão, Almeida Filho (2006, p. 4) afirma que:

Para usufruir de uma competência profissional concebida sob critérios de composição e ação contemporaneamente desejáveis, os professores partirão[...] de uma competência implícita crescentemente evidenciada e explicada, combinada com outra competência essencial, a de poder usar a língua-alvo que também se pode descrever em termos próprios (de sua gramática, fonologia, articulação discursiva etc).

Em outras palavras, evidencia-se a necessidade de trabalho conjunto entre: (a) competências propriamente relacionadas ao agir docente, construídas por meio de evidências de situações percebidas na prática e explicadas por meio de embasamentos teóricos adquiridos pelo professor em formação inicial e/ou continuada; e (b) competências linguístico-discursivas que englobam conhecimentos e habilidades desenvolvidas com base na língua-alvo.

Corroborando com as duas visões de competências, ao apresentar uma lista de conhecimentos básicos necessários ao docente, Shulman (1987) distinguiu o conhecimento pedagógico do conhecimento disciplinar, apontando cada um desses separadamente. Entre outros conhecimentos relacionados ao contexto educacional como currículo, programas, materiais, organização e valores, as noções de conhecimento pedagógico e disciplinar estão respectivamente relacionadas às competências docentes e linguístico-discursivas, as quais serão brevemente apresentadas a seguir.

\section{Competências do Agir Docente}

Inicialmente, ao pensar o papel desempenhado pelo docente como educador e formador, a comunidade, não somente escolar, mas de um modo geral, tem expectativas sobre sua atuação, idealizando um profissional competente localizado em espaço e tempo de acordo com seu contexto de atuação (CUNHA, 1996). Assim sendo, por meio do desenvolvimento de competências do agir docente na graduação e formação docente, busca-se aperfeiçoar o modo pelo qual o professor irá cumprir seu papel. 
Neste âmbito, Perrenoud (2000, p. 14) elencou e descreveu uma lista de 10 famílias de competências, visando nortear a prática docente: 1. Organizar e estimular situações de aprendizagem; 2. Gerar a progressão das aprendizagens; 3. Conceber e fazer com que os dispositivos de diferenciação evoluam; 4. Envolver os alunos em suas aprendizagens e no trabalho; 5. Trabalhar em equipe; 6. Participar da gestão da escola; 7. Informar e envolver os pais; 8. Utilizar as novas tecnologias; 9. Enfrentar os deveres e os dilemas éticos da profissão; 10. Gerar sua própria formação contínua.

A partir dessa lista de competências ligadas ao "saber-fazer" na docência, o autor ponderou a necessidade de desenvolvimento conjunto de tais famílias, uma vez que não são definitivas em si. Mais adiante em seus estudos, Perrenoud (2001) apresentou a insuficiência de competências mais amplas para se proceder na prática docente, frisando a transposição didática na formação profissional, ponto este a ser questionado por meio da visão dicotômica analisada neste trabalho.

Por este viés, na formação de professores de LE, o desencanto com as disciplinas relacionadas ao agir docente surgem pelo fato da distância entre a realidade prática da profissão e os conhecimentos teóricos e científicos aos quais são expostos. Zabalza (2004) questiona a relevância desta formação para os graduandos em aspectos como conteúdo, metodologias e processos envolvidos nesta etapa. Corroborando este pensamento, nas pesquisas de Castro (2006), a autora aponta a urgência de envolvimento dos futuros professores, alunos de Letras, com a profissão.

\section{Competências Linguístico-discursivas}

A formação docente envolve prioritariamente o desenvolvimento de competências do agir docente, as quais são componentes da licenciatura em Letras e não de outras disciplinas que desenvolvam habilidades diversas em LE, como por exemplo, oralidade e escrita (CASTRO, 2006). Por outro lado, as competências linguístico-discursivas necessitam de um olhar muito atencioso, uma vez que compõem conhecimentos necessários na atuação do professor de LE. 
Por esse viés, Johnson e Freeman (2001) postularam que na formação docente, o conteúdo relacionado à segunda língua envolve conhecimentos mais voltados para a disciplina em si. Assim sendo, a aquisição de LE na formação docente é direcionada à aspectos estruturais e semânticos da própria LE, sendo as competências desta ordem desenvolvidas por meio das principais habilidades linguísticas (ler, escrever, ouvir e falar).

Nesta ordem, as competências linguístico-discursivas são trabalhadas com o aluno-professor no intuito de formá-lo linguisticamente, ou seja, a aquisição linguística requerida pelo docente de LE para sua atuação profissional passa a ser prioridade de disciplinas da graduação diretamente relacionadas à aprendizagem da língua. Assim sendo, tais disciplinas se caracterizam por um processo de aprendizagem de uma determinada habilidade por meio de aspectos estruturais que requerem o desenvolvimento de estratégias de aprendizagem.

Por um lado, o fato de aprender uma LE pode auxiliar o profissional a compreender o processo de aprendizagem de línguas, levando-o a estabelecer métodos e estratégias para então atuar no ensino de LE. Por outro lado, como muito deste conhecimento não é voltado para sala de aula, mas sim, para a aprendizagem de LE do próprio graduando, o conteúdo acaba se tornando não funcional para seu contexto de atuação (CLARKE, 1994 apud JOHNSON; FREEMAN, 2001).

Mais uma vez a ideia de transposição didática (PERRENOUD, 2001) se faz necessária para validar a importância da construção de competências linguístico-discursivas. Neste ponto, ao invés de opor ou sobrepor conhecimento disciplinar e pedagógico, cabe fazer junção das duas visões para criar maiores paradigmas e práticas de análise da formação docente.

\section{Pesquisa com Alunos-Professores}

Apesar de terem sido apresentados aspectos relacionados à formação docente de um modo geral, o estudo realizado teve como foco o curso de graduação em Letras, sendo o momento de formação inicial docente colocado em questão. Essa pesquisa de natureza 
qualitativa tomou como base a análise de respostas discursivas dos sujeitos por meio da aplicação de em questionário (Apêndice I) relacionado às competências desenvolvidas na graduação e, também, ao seu ponto de vista no sentido de avaliar e sugerir melhorias ao curso. As questões foram respondidas online, mediante assinatura de termo de consentimento (Apêndice II), esclarecendo o modo de participação.

Com relação à delimitação dos sujeitos dessa pesquisa, inicialmente, todos professores de inglês na Educação Básica e/ou escolas de idiomas de uma cidade do Norte do Paraná foram convidados a participar da pesquisa presencialmente nos contextos de atuação em que se inserem, uma vez que a pesquisadora foi em busca de professores de Língua Inglesa, graduados e graduandos em Letras, com experiências nessa licenciatura e no ensino de LE. Ao apresentar a proposta de pesquisa, os sujeitos que aceitaram participar, permitiram o envio do questionário por e-mail, para que pudessem respondê-los dentro de um prazo de sete dias, estabelecido a partir da data de envio do questionário por e-mail. Dos 12 professores apresentados à proposta, dos quais todos aceitaram a participação na pesquisa, seis enviaram o questionário respondido no prazo estabelecido. Os demais, não retornaram ou enviaram o questionário após o prazo.

Com o intuito de perceber a visão do próprio docente sobre sua formação inicial, seis professoras de inglês atuantes em diferentes contextos educacionais participam dessa pesquisa, sendo todas atuantes em escola de idiomas, três delas também inseridas em escolas particulares e uma em escolas estaduais da mesma cidade. É importante ressaltar que, neste trabalho, os sujeitos serão denominadas por $\mathbf{P}$ e enumerados para que sejam diferenciados, porém, não identificados.

Dentre os sujeitos, todas passaram por diferentes formações acadêmicas do curso de Letras em três universidades diferentes: três cursaram Letras Português/Inglês, sendo duas delas à distância, e três cursaram Letras Estrangeiras com habilitação em Língua Inglesa. Nesta ordem, as duas professoras que estudaram à distância cursaram Letras em universidade particular e as demais, em universidades públicas, sendo que todas eram localizadas no Paraná. Ainda, duas delas encontram-se cursando o último ano da graduação. 
Primeiramente, para o desenvolvimento do questionário, as professoras foram apresentadas por meio de um breve texto explicativo às competências docentes e linguístico-discursivas, para que pudessem visualizar a relação entre suas experiências e cada uma das competências distinguidas nesta pesquisa (Apêndice I). Deste modo, conforme a realização do questionário, as professoras puderam enviar o material por e-mail dentro do prazo estabelecido, para que fossem submetidas à analise.

\section{Análise e Discussão de dados}

Para organizar os dados gerados por meio do questionário discursivo aplicado, foram analisadas as questões individualmente, sendo ressaltados os principais aspectos levantados pelos sujeitos, conforme apresento a seguir.

Questão 1. Em quais disciplinas e atividades desenvolvidas na graduação as competências docentes foram desenvolvidas?

Nesta primeira questão, os sujeitos mencionaram de modo geral disciplinas relacionadas à educação e ao ensino de línguas na Educação Básica, como Psicologia da Educação, Prática de Ensino de Línguas (Inglês e Português) e Didática. Somente duas delas não mencionaram a disciplina de Estágio, e uma delas ainda destacou a importância da prática de sala de aula da seguinte maneira:

Acredito que as competências docentes são verdadeiramente desenvolvidas com a experiência que cada um vai adquirindo com o tempo [...].(P6)

Outro aspecto apresentado por P4 foi a questão do exemplo do profissional observado com base na atuação do próprio docente na formação inicial professores, ou seja, a relevância do formador na construção de competências docentes, como evidenciado no trecho a seguir:

Acredito que todas as matérias mostram um pouco das competências docentes já que os próprios alunos avaliam as aulas de seus professores sendo espelho para uma futura prática. [...] as matérias que 
me levaram a refletir/ atuar como docente foram algumas aulas de Produção Oral Inglês (pois observava a atuação da teacher) [...] (P4)

Nesse sentido, P3 associou a disciplina de Linguística Aplicada às competências docentes:

[...] posso mencionar também a disciplina de linguística aplicada, uma vez que nela nós refletimos sobre as metodologias de modo amplo. (P3)

De caráter teórico, a disciplina referida por P3 foi ambiente de discussões para questões práticas que envolvem a atuação do profissional de Letras. Pode-se inferir que, por se tratar de uma disciplina não relacionada diretamente com o ensino de LE na Educação Básica, a abordagem adotada pelo formador tenha sido pensada neste sentido.

Assim, tanto o formador quanto a abordagem teórica da disciplina implicam na contribuição do desenvolvimento de competências docentes no que tange a atuação profissional. Embora as disciplinas tenham se relacionado, sobretudo, com o ofício de professor propriamente dito, reforçando aspectos como educação, didática e ensino, surgiram dois aspectos importantes desta questão: a) o perfil do formador e b) o conteúdo abordado nas disciplinas.

Tais pontos refletem a importância de uma formação docente que contemple não somente o graduando, mas aspectos relacionados ao seu ambiente de formação como um todo. O professor formador precisa de uma boa formação para que possa desenvolver profissionais bem formados e ainda, para que as abordagens dos conteúdos sejam voltadas às necessidades do indivíduo em formação.

\section{Em quais disciplinas e atividades desenvolvidas na graduação as competências linguistico-discursivas}

\section{foram desenvolvidas?}

Inicialmente, cabe ponderar que por se tratar de competências linguístico-discursivas, todos os sujeitos destacaram de antemão a disciplina de LI em suas variedades envolvendo as quatro habilidades (oral, escrita, auditiva e leitora). Deste modo, o desenvolvi- 
mento dessas competências foi diretamente relacionado à execução de atividades relacionadas ao programa destas disciplinas, como produções textuais, práticas de conversação, estudos e exercícios de gramática e apresentações de trabalhos em LI.

Nesta ordem, disciplinas mais específicas como Fonética e Fonologia, Léxico e Literatura foram apontadas nas respostas como contribuidoras na aquisição linguística e de domínio discursivo da LE. Ainda, como metade dos sujeitos esteve inserida em cursos de habilitação dupla (Português/Inglês), eles relacionaram o desenvolvimento das quatro habilidades também em Língua Portuguesa.

Por se tratar da parte mais específica da formação dos professores de línguas, o desenvolvimento destas competências foi associado somente por uma das participantes a outras disciplinas:

De modo específico, na disciplina de LÍNGUA INGLESA e FONÉTICA E FONOLOGIA [grifos do sujeito]. De modo indireto, em todas as outras que eram ministradas em inglês (linguística aplicada, literatura, metodologia) [...] (P3)

Deste modo, pode-se observar que o conteúdo linguístico aparece por vezes mais associado às disciplinas as quais o desenvolvem e que, embora para P3 o fato de outras disciplinas serem ministradas em LI indique o desenvolver linguístico-discursivo, ainda assim, o ensino da língua como um objeto de estudo é evidente nas práticas desenvolvidas nas disciplinas referidas.

3. Como você avalia o modo em que tais competências (docentes e linguístico-discursivas) auxiliam na sua atuação profissional?

Ao avaliar as competências em questão, os sujeitos compartilharam os seguintes pontos em comum: 1. Contribuição teórica superior ao desenvolvimento da prática; 2 . Insuficiência da graduação com relação às competências.

No primeiro ponto de convergência, os sujeitos se referem ora a importância da teoria, ora ao modo como auxiliam na atuação profissional, como se observa nos seguintes trechos: 
[...] auxiliam diretamente. Para toda prática existe uma teoria por traz. (P3)

[...] ajudam a compreender melhor não somente as nossas habilidades linguísticas e desenvolve-las, mas também [...] o papel do professor no âmbito do ensino ao qual estará inserido. (P1)

Por outro lado, a insuficiência da graduação é apontada por todas as participantes com relação à prática, aqui referida como atuação profissional:

[...] contribuíram para minha prática docente muito mais na parte teórica do que prática. (P2)

Acho que foi um rumo/caminho que foi dado quando iniciamos o curso, porém acredito que a prática poderia ser mais trabalhada. (P4)

[...] contudo, posso afirmar que o que vi na universidade não foi suficiente. Foram as necessidades que a prática docente foi revelando que me fizeram pesquisar mais. (P3)

Por meio desses relatos, a questão pareceu levantar certo descontentamento com aquilo que se recebe da graduação em Letras, visto que o desenvolvimento de competências é de fato reconhecido para sujeitos, porém, ao se depararem com a prática docente, necessitam de mais preparação para que isso aconteça, ou até mesmo como afirmou P4, mais embasamento teórico para atuar.

\section{O que você sugere para melhorar aspectos da atuação profissional por meio da formação acadêmica?}

Visando investigar o modo como os sujeitos associam a qualidade da formação inicial à atuação profissional, solicitei sugestões para contribuírem com aspectos diretamente ligados à graduação. Com base nas experiências de cada uma delas, e também considerando que iniciaram e finalizaram seus cursos entre os anos de 1998 e 2017, foi possível observar algumas regularidades relacionadas a necessidades de mudanças e medidas a serem tomadas no curso de Letras. 
$\mathrm{Na}$ tabela a seguir, foram levantados os aspectos em comum abordados pelas participantes, os quais foram listados e suportados com argumentos apresentados nos questionários.

Quadro 1. Aspectos sugeridos ao curso de Letras.

\begin{tabular}{|l|l|}
\hline \multicolumn{1}{|c|}{ Aspectos de convergência } & \multicolumn{1}{|c|}{ Argumentos embasadores } \\
\hline $\begin{array}{l}\text { 1. As disciplinas, de modo geral, se- } \\
\text { rem mais voltadas às práticas do- } \\
\text { centes; }\end{array}$ & $\begin{array}{l}\text { Sugiro que as disciplinas sejam mais voltadas à prática } \\
\text { docente, onde os alunos pratiquem o: preparar aula, dar } \\
\text { aula. Onde eles possam compartilhar experiências, reco- } \\
\text { nhecer seus erros e se ajudar. (P2) }\end{array}$ \\
\hline $\begin{array}{l}\text { 2. A reflexão sobre as teorias e de- } \\
\text { monstração prática de suas aplica- } \\
\text { ções; }\end{array}$ & $\begin{array}{l}\text { Melhor organização do currículo. Também, é preciso } \\
\text { que quando se ensine teoria haja uma reflexão e mesmo } \\
\text { uma demonstração na prática. (P3) }\end{array}$ \\
\hline $\begin{array}{l}\text { 3. Mais atenção e supervisão aos } \\
\text { estágios realizados pelos graduan- } \\
\text { dos nas escolas. }\end{array}$ & $\begin{array}{l}{[\ldots . \text { aulas práticas, estágios mais e melhor supervisiona- }} \\
\text { dos, estágios obrigatórios também na educação infantil. } \\
\text { (P6) }\end{array}$ \\
\hline $\begin{array}{l}\text { [... Outro ponto é haver mais acompanhamento nos es- } \\
\text { tágios supervisionados. (P4) }\end{array}$ \\
\hline
\end{tabular}

Fonte: As autoras.

Embora o período de realização das graduações aqui abordadas tenha ocorrido nas duas últimas décadas, é evidente que os sujeitos dos variados contextos de formação inicial e também atuação, tenham percebido uma deficiência no que tange a prática docente. No início deste trabalho, corroborando com Perrenoud (2002), o domínio de conteúdos da disciplina a qual lecionam e a área de Letras especificamente não aparecem como pontos a serem repensados nestas sugestões, o que leva a inferir que são prioritariamente abordados na formação inicial.

Nesse sentido, as competências docentes carecem de maior atenção, uma vez que nos três aspectos levantados a partir das sugestões das participantes, a questão da prática do ofício de professor em atividades acadêmicas (como o estágio supervisionado), disciplinas e nas teorias necessitam de melhorias. 
Outro ponto relevante é a questão da teoria versus prática, levantado no segundo aspecto apresentado na tabela. Ao que Perrenoud (2010) se referiu como transposição didática, cabe à formação docente desenvolver meios para que o aluno-professor possa utilizar os conhecimentos teóricos e transpor informações ao realizar a prática docente e ainda, mais diretamente falando do professor de LI focado neste trabalho, por meio das próprias competências linguístico-discursivas desenvolvidas a partir da graduação.

Ainda neste aspecto, para Johnson e Freeman (2001), professores precisam de oportunidades múltiplas para analisar o conhecimento teórico que recebem em sua formação e deste modo, poderem aliá-los às suas práticas. Para os autores, quando vistos em contexto de uso, os conhecimentos teóricos se correlacionam mais facilmente à prática.

Neste âmbito, analisar o professor como aprendiz de professor implica vê-lo como professor e não aluno de uma LE (JOHNSON; FREEMAN, 2001). Cabe, então, na formação docente, considerar o indivíduo, bem como sua capacidade e modo de aprender. Por isso, o contexto de formação deve ser meio de reformulação de conhecimentos, valores e crenças individuais levadas pelo profissional em seu ensino, para que possam trabalhar efetivamente e desenvolverem amplamente as competências docentes.

Por fim, um aspecto isolado apresentado por P4 leva a uma reflexão além do que é ofertado no curso de Letras em termos de ensino e aprendizagem do aluno-professor:

[...] o primeiro passo a ser dado é o Professor Universitário fazer uma reflexão de sua prática. Se a abordagem que utiliza, é a mesma que vem sendo utilizada há algum tempo, ou ele tem se atualizado, e procura buscar estratégias e ideias para envolver os alunos em sala na universidade. Se o próprio aluno não se sente motivado ou instigado a aprender, algo está errado. Educadores tem um papel fundamental de fazer o aluno gostar ou se sentir motivado pela sua matéria. (P4)

A partir desta sugestão, a discussão se abre para aspectos da formação no que tange o papel do próprio formador. Anteriormente, a representação deste profissional apresentada na questão dois, interpretada como um exemplo de postura para os alunos-professores em formação inicial, o professor-formador pode ser visto muitas vezes como um modelo 
para a prática docente do aluno-professor, o que reforça a importância de sua prática e logo, de sua formação continuada. Assim, esta discussão implica um novo estudo a se fazer, como base no professor-formador, uma vez que aparece como a raiz desta reflexão.

De modo geral, as respostas dos sujeitos refletiram que, muito embora a graduação seja um ambiente no qual se espera o desenvolvimento de competências para o exercício da profissão docente, os alunos-professores continuam seu aprendizado por meio de experiência profissional. Conforme Perrenoud (2002) afirmou não há como antecipar todas as situações que surgirão no decorrer da profissão durante a formação inicial do professor. Sendo assim, a prática reflexiva surge como uma possibilidade de visão positiva desta experiência e, ainda, esta não deve ser esquecida posteriormente a esta etapa de formação (PERRENOUD, 2002).

Corroborando a perspectiva de formação do professor a partir da formação inicial, Johnston e Freeman (2001) enfatizaram a natureza social da formação de professores e a partir dessa visão social, os alunos-professores aprendem como ensinar e lidar com o trabalho envolvendo sala, alunos e comunidade. Assim, as respostas evidenciaram a necessidade de uma visão epistemológica mais aberta para como os professores colocam em prática o que aprendem.

\section{Considerações Finais}

Neste trabalho, buscamos apresentar a visão de (ex-)alunas do curso de Letras sobre as competências do agir docente e linguístico-discursivas, desenvolvidas a partir da formação docente. Acreditando na relevância da formação continuada para desenvolvimento interminável e renovável de tais competências, apresentamos embasamento teórico para a formação docente de modo geral, visando pesquisar professores em serviço e em pre-serviço de um curso de Letras, os quais se encontram em formação inicial e/ou continuada e percebem as necessidades da prática docente, além do contexto de formação inicial.

Da análise aqui realizada sobre a graduação em Letras, com base nas experiências dos sujeitos, pode-se considerar que: (a) há mesmo uma diferença no desenvolvimento das 
competências do agir docente e linguístico-discursivas neste contexto de formação, sendo possível perceber que o agir docente, ou seja, o desenvolvimento da prática docente necessita de mais atenção em diversos fatores, como conteúdo, disciplinas, organização curricular, supervisão de estágios; (b) a representação do papel do professor-formador apareceu de algumas formas no discurso das participantes, revelando sua importância para o desenvolvimento da prática docente, sobretudo em contexto inicial.

Deste modo, as necessidades de maior direcionamento às práticas docentes, bem como reflexão sobre teorias e sua aplicabilidade, além do melhoramento da supervisão dos estágios de docência apontadas por estudantes de Letras podem ser resolvidas aliando estes dois pontos de análise. Partindo de um profissional formador competente, com objetivos bem definidos com relação à formação inicial de alunos-professores, juntamente a um currículo que contemple ainda mais a prática profissional docente, o curso de graduação, então, pode oferecer condições mais concretas de embasamento profissional para a atuação docente.

\title{
COMPETENCES OF TEACHER-STUDENTS: AN OVERVIEW ON THE INITIAL TEACHER TRAINING IN ENGLISH LANGUAGE
}

\begin{abstract}
This study was carried out based on the experiences of students of Letras course with major in English Language by universities located in Paraná State, from 1998 to 2017, aiming at investigating the relevance of developing teaching act and linguistic-discursive competences, concerning the teaching practice in different educational contexts. Based on the disciplines and academic activities offered by Letras course, focused on developing such competences in a dissociated way (CASTRO, 2006) and also focusing on the student-teacher, considered as teacher learner and not a Foreign Language learner (JOHNSON \& FREEMAN, 2001), it was conducted a qualitative investigation survey by a discursive questionnaire, about the role competences play in teaching professional performance and how this relation is lived and interpreted by professionals since the beginning of their process of formation in graduation course. In this way, itis expected to contribute to the research in teacher training in Letras area, related to the building of professional competences mainly on initial formation.
\end{abstract}

KEYWORDS: Teacher Training; Competences; English Language. 


\section{REFERÊNCIAS}

AKBARI, R. Reflections on reflection: A critical appraisal of reflective practices in L2 teacher education. System, v. 35, p. 192-207, 2007.

ALMEIDA FILHO, J. C. P. Conhecer e desenvolver a competência profissional dos professores de LE. 2006.

BONFIM, B. B. S. B; CONCEIÇÃO, M. P. A formação de professores de línguas estrangeiras no Brasil. In: SILVA, K. A.; DANIEL, F. G.; KANEKO-MARQUES, S. M.; SALOMÃO, A. C. B. (Org.). A formação de professores de línguas: novos olhares - volume III. Campinas, SP: Pontes Editores, 2014.

BRASIL. Parecer CNE/CES No 492/2001, de 03 de abril de 2001. Recomenda a aprovação das propostas diretrizes dos cursos de Filosofia, História, Geografia, Serviço Social, Comunicação Social, Ciências Sociais, Letras, Biblioteconomia, Arquivologia e Museologia. MEC, Brasília. Disponível em: http:/ / portal.mec.gov.br/cne/arquivos/pdf/CES0492.pdf. Último acesso em 11 de julho de 2017.

CASTRO, S. T. R. Mapeando a pesquisa em formação de professores de língua estrangeira em cursos de Letras na Linguística Aplicada. In: CASTRO, S. T. R.; SILVA, E. R. (Org.). Formação do profissional docente: contribuições de pesquisas em Linguística Aplicada. Taubaté: Cabral Editora, 2006.

CONTRERAS, J. Contradições e contrariedades: do profissional reflexivo ao intelectual crítico. In: . A autonomia de professores. São Paulo: Cortez, 2002.

CUNHA, M. I. O Bom professor e sua prática. Campinas, SP: Papirus, 1996

GIMENEZ, T. Formação de professores de línguas no Brasil: avanços e desafios. In: SANTOS, L. I. S.; SILVA, K. A. (Org.). Linguagem, ciência e ensino: desafios regionais e globais. Campinas, SP: Pontes Editores, 2013.

JOHNSON, K.; FREEMAN, D. Teacher learning in second language teacher education: a socially-situated perspective. Revista Brasileira de Linguistica Aplicada, v. 1, n.1, p. 53-69, 2001 .

JORGE, MLS. Prática de Ensino de Inglês: o estágio como experiência integradora da teoria, reflexão e prática. In: CARMAGNANI A.M.G. \& GRIGOLETTO, M. (orgs.) Inglês como língua estrangeira: identidade, práticas e textualidade. São Paulo: Humanitas/FFLCH/USP, p. 499-508, 2001.

MATEUS, E. Torres de babel e línguas de fogo: um pouco sobre pesquisa na formação de professores de inglês. Revista Brasileira de Linguística Aplicada, v. 9, n.1, 2009.

PERRENOUD, P. Novas competências para ensinar. Trad. Patrícia Chittoni Ramos. Porto Alegre: Artmed, 2000. 
PERRENOUD, P. Saber refletir sobre a própria prática: objetivo central da formação dos professores? In: - A Prática reflexiva no ofício de professor: profissionalização e razão pedagógica. Porto Alegre: Artmed, 2002.

PERRENOUD, P. et al. Formando Professores profissionais. Porto Alegre. Artmed Editora, 2001.

RESOLUÇÃO CNE/CP 2, DE 19 DE FEVEREIRO DE 2002. Institui a duração e a carga horária dos cursos de licenciatura, de graduação plena, de formação de professores da Educação Básica em nível superior. Disponível em: http://portal.mec.gov.br/cne/arquivos/ pdf/CP022002.pdf. Último acesso em 11 de julho de 2017.

RICHARDS, Jack C. Theories of teaching in language teaching. Methodology in language teaching: An anthology of current practice, p. 19-25, 2002.

SHULMAN, L. S. Knowledge and teaching: Foundations of the new reform. Harvard Educational Review, v. 57, p. 114-135.1987.

SCHULZ, Renate A. Foreign language teacher development: MLJ perspectives-19161999. The Modern Language Journal, v. 84, n. 4, p. 495-522, 2000.

WALLACE, M. Teacher education: some current models. In: Training foreign language teachers: a reflective approach. Cambridge: CUP, 1991.

WILBUR, Marcia L. How foreign language teachers get taught: Methods of teaching the methods course. Foreign Language Annals, v. 40, n. 1, p. 79-101, 2007.

ZABALZA, M. A. O ensino universitário: seu cenário e seus protagonistas. Porto Alegre: Artmed, 239 p. 2004.

ZEICHNER, Kenneth M. Alternative paradigms of teacher education. Journal of teacher education, v. 34, n. 3, p. 3-9, 1983. 